\title{
Analisis Kepercayaan Konsumen, Kualitas Produk, Kualitas Website, Dan Kualitas Pelayanan Terhadap Keputusan Pembelian
}

\author{
Erlitawati Kaharudin', David Triyono², Alexander Nova Vernando ${ }^{3}$
}

\section{1,2,3Program Studi Kewirausahaaan Akademi Entrepreneuship Terang Bangsa}

\begin{tabular}{|c|c|}
\hline INFO ARTIKEL & \\
\hline $\begin{array}{l}\text { Sejarah Artikel: } \\
\text { Diterima : } 2021 \\
\text { Diperbaiki : } 2021 \\
\text { Disetujui : } 2021 \\
\text { Keywords: } \\
\text { costumer trust, } \\
\text { product quality, } \\
\text { purchase decision, } \\
\text { service quality, web } \\
\text { quality. }\end{array}$ & $\begin{array}{l}\text { The purpose of this study is to identify the factors that influence purchasing } \\
\text { decisions on shopping at Tokopedia. The dependent variable in this study is } \\
\text { purchasing decisions }(Y) \text { dan the independent variables are customer trust }\left(X_{1}\right) \text {, } \\
\text { product quality }\left(X_{2}\right) \text {, website quality }\left(X_{3}\right) \text {, and service quality }\left(X_{4}\right) \text {. The population } \\
\text { of this study are consumers who have made purchases at Tokopedia. This study } \\
\text { used } 100 \text { respondents. Sampling was done by purposive sampling technique } \\
\text { (non-probability sampling) using random sampling based on certain } \\
\text { considerations. The results showed that the variables of customer trust }\left(X_{1}\right) \text {, } \\
\text { product quality }\left(X_{2}\right) \text {, website quality }\left(X_{3}\right) \text {, and service quality }\left(X_{4}\right) \text { simultaneously } \\
\text { and partially have a positive influence on purchasing decisions }(Y) \text {. The } \\
\text { multicollinearity regression shows that there is no heteroscedasticity, and is } \\
\text { normally distributed. The value of determination is } 0.727 \text {, which means } 72.7 \% \text { of } \\
\text { the variation in the purchasing decision variables in the model can be determined } \\
\text { by the variables of consumer confidence, product quality, website quality, and } \\
\text { service quality. }\end{array}$ \\
\hline & \\
\hline $\begin{array}{l}\text { Kata } \\
\text { keper } \\
\text { keput } \\
\text { kuali } \\
\text { kual } \\
\text { kuali }\end{array}$ & $\begin{array}{l}\text { Tujuan dari penelitian ini untuk mengidentifikasi faktor-faktor yang } \\
\text { mempengaruhi keputusan pembelian belanja di Tokopedia. Variabel } \\
\text { bebas dalam penelitian ini adalah kepercayaan pelanggan }\left(\mathrm{X}_{1}\right) \text {, kualitas } \\
\text { produk }\left(\mathrm{X}_{2}\right) \text {, kualitas website }\left(\mathrm{X}_{3}\right) \text {, dan kualitas layanan }\left(\mathrm{X}_{4}\right) \text {, dengan } \\
\text { variabel terikatnya adalah keputusan pembelian }(\mathrm{Y}) \text {. Populasi yang } \\
\text { dipilih adalah penelitian ini adalah mereka yang telah melakukan } \\
\text { transaksi pembelian di Tokopedia. Penelitian ini menggunakan } 100 \\
\text { responden. Pengambilan sampel dilakukan dengan teknik purposive } \\
\text { sampling (non probability sampling) yang menggunakan random sampling } \\
\text { berdasarkan pertimbangan tertentu. Hasil penelitian menunjukkan bahwa } \\
\text { variabel kepercayaan pelanggan }\left(\mathrm{X}_{1}\right) \text {, kualitas produk }\left(\mathrm{X}_{2}\right) \text {, kualitas } \\
\text { website }\left(\mathrm{X}_{3}\right) \text {, dan kualitas pelayanan }\left(\mathrm{X}_{4}\right) \text { secara simultan dan parsial } \\
\text { memiliki pengaruh positif terhadap keputusan pembelian }(\mathrm{Y}) \text {. Uji asumsi } \\
\text { klasik yaitu model regresi multikolinieritas menunjukkan tidak terjadi } \\
\text { heteroskedastisitas, dan berdistribusi normal. Nilai determinasi sebesar } \\
\text { 0,727 yang berarti } 72.7 \% \text { variasi variabel keputusan pembelian pada } \\
\text { model dapat diterangkan oleh variabel kepercayaan konsumen, kualitas } \\
\text { produk, kualitas website dan kualitas pelayanan }\end{array}$ \\
\hline \multicolumn{2}{|c|}{$\begin{array}{l}\text { Korespondensi: } \\
\text { Nama : Erlitawati Kaharudin } \\
\text { Email : erlitakaharudin@gmail.com }\end{array}$} \\
\hline
\end{tabular}


Analisis Kepercayaan Konsumen, Kualitas Produk, Kualitas Website,...

Erlitawati Kaharudin, David Triyono, Alexander Nova Vernando

\section{PENDAHULUAN}

Di era globalisasi ini, dunia mengalami perubahan yang pesat. Tehnologi bergeser dari dunia mekanis ke digital yang berdampak terhadap perilaku konsumen. Perangkat tehnologi serta internet membawa banyak kemajuan di berbagai aspek. Tehnologi dan internet menyebabkan manusia dapat bekerja dengan lebih praktis serta efisien. Perkembangan tehnologi dapat menjadikan jarak yang jauh bisa didekatkan.

Jika distatistikkan pengguna internet di Indonesia hingga Mei 2020 menduduki urutan ketujuh di antara negara - negara di Asia. Di Indonesia pengguna internet sebesar 212.350.000 dari populasi sekitar 276.300.000 jiwa. Hasil survey Asosiasi Penyelenggara Jasa Internet Indonesia memperlihatkan di Indonesia pengguna internet tahun 2020 berjumlah 196.000.000an orang atau sekitar $74 \%$ dari total penduduk Indonesia terjangkau internet. (Annur, n.d.)

Saat ini pandemi covid melanda seluruh dunia, tidak terkecuali Indonesia dan ini membawa dampak pada perubahan perilaku pengguna internet secara masif. Mau tidak mau manusia bergerak ke perubahan gaya hidup secara digital. Dengan adanya pandemi covid-19 penguna internet mengalami peningkatan di berbagai sektor. Tren belanja online di tengah masyarakat Indonesia melonjak, dikarenakan kemudahan bertransaksi tanpa harus bertatap muka yang bisa mengurangi resiko terpapar covid. Beberapa tahun terakhir jual beli online mengalami peningkatan yang sangat pesat. Pelaku transaksi online bukan hanya kalangan atas tetapi juga dilakukan oleh kalangan menengah ke bawah.

Perilaku pembelian secara online memiliki keuntungan berupa kepraktisan, dimana konsumen dapat melakukan transaksi di rumah, di kantor atau dimanapun, dan kapan saja serta barang diantar sampai di tempat. Daya tarik dalam bisnis online antara lain adalah waktu kerja fleksibel, promosi mudah, jangkauan luas, modal usaha kecil.

Banyak faktor yang dipertimbangkan oleh konsumen sebelum melakukan keputusan pembelian online/daring. Kelebihan belanja online antara lain praktis tanpa harus mendatangi lokasi, dapat membandingkan harga antar marketplace, pembayaran dapat dilakukan secara online, banyak promo atau voucher yang ditawarkan serta mengurangi kontak langsung dengan orang lain yang bermanfaat terutama di masa pandemi. Kekurangan belanja online/daring misalnya konsumemn tidak melihat atau menyentuh barang secara langsung sehingga barang yang dibeli tidak sesuai dengan harapan, barang tidak dapat langsung dibawa pulang, , rawan penipuan serta tidak semua orang dapat memakai aplikasi online/daring.

Seseorang membeli suatu produk secara online karena dipengaruhi beberapa faktor, salah satunya adalah kepercayaan konsumen. Kepercayaan konsumen terhadap toko online, produk akan tercipta ketika dapat diandalkan dan sesuai dengan harapan konsumen. Kepercayaan konsumen akan mempengaruhi di dalam mengambil keputusan pembelian bahkan pembelian ulang.

Kualitas produk merupakan salah satu faktor yang akan dipertimbangkan konsumen di dalam pengambilan keputusan pembelian. Berbeda dengan transaksi offline, dalam transaksi online konsumen tidak dapat melihat atau menyentuh rpoduk yang akan dibeli. Konsumen dapat melakukan penilaian dari ulasan konsumen yang pernah membeli atau ketika produk telah sampai ditangan konsumen. Website suatu marketplace akan memberikan gambaran perusahaan kepada konsumen.

Kualitas pelayanan salah satu faktor yang dipertimbangan konsumen dalam mengambil keputusan pembelian. Pelayanan yang baik diharapkan dapat meningkatlkan penjualan.

Dari uraian di atas maka dalam penelitian ini dikemukakan beberapa variabel yang dianggap berpengaruh dalam keputusan pembelian konsumen secara online yakni kepercayaan konsumen, kualitas produk, website serta pelayanan.

\section{KAJIAN PUSTAKA}

\section{Kepercayaan Konsumen}

Kepercayaan konsumen (consumer trust) sangat penting untuk menjalin hubungan anatara konsumen dan produsen. Kepercayaan konsumen adalah suatu kepercayaan yang diberikan oleh pihak pembeli kepada penjual dalam memenuhi janji-janji yang diberikan. Kepercayaan dibangun agar konsumen merasa aman, percaya dan menjadikan konsumen menjadi pelanggan yang setia. 
Kepercayaan adalah kemauan pihak perusahaan untuk mempercayakan mitra bisnis (Kotler, Philip; Keller, 2016). Kepercayaan dipengaruhi oleh sejulmlah faktor interpersonal dan antar organisasi. Ada dua hal yang berbeda dalam kepercayaan yaitu kreibilitas dan niat baik atau benevolence/good will. Kredibilitas yaitu keahlian ketika melaksanakan tugas dengan baik dan dapat dipercaya. Benevolence/good will atau niat baik merupakan kesanggupan untuk menjalankan kesepakatan bersama. Dalam dunia online kepercayaan menjadi salah satu pertimbangan konsumen karena barang atau jasa yang diperdagangankan tidak dapat dilihat terlebih dahulu, begitu juga belum tentu ada jaminan setelah uang dikirim konsumen akan memperoleh produk yang dibeli.

Kepercayaan dari konsumen kepada penjual terwujud ketika penjual mampu memberikan jaminan keamanan kepada konsumen. Di dalam situs online shopping biasanya akan ditampilkan informasi tentang para penjual yang lapaknya sering di akses oleh pengunjung.

\section{Kualitas Produk}

Kualitas merupakan semua ciri serta karakteristik fitur dan karakteristik produk dan jasa untuk memuaskan kebutuhan yang terlihat maupun tidak (Kotler \& Keller, 2016). Konsep produk meliputi barang, kemasan, merk, label, pelayanan, dan jaminan atau garansi. Dalam situasi persaingan bisnis online, persoalan kualitas produk menjadi pertimbangan yang sangat penting. Kualitas produk diukur sejauhmana produk tersebut bisa memuaskan konsumen.

\section{Kualitas Website}

Metode webqual digunakan untuk menganalisa kualitas suatu website yang didasarka pada persepsi end user atau pengguna akhir. Untuk mengukur kualitas website dapat menggunakan tiga variabel yang dapat memberikan informasi akurat yaitu kualitas interaksi, kegunaan serta kualitas kualitas informasi.

\section{Kualitas Pelayanan}

Pelayanan merupakan perilaku produsen untuk memenuhi kepuasan konsumen. Pelayanan merupakan aktivitas yang diberikan oleh salah satu pihak ke pihak yang lain (Kotler,2016). Kualitas pelayanan sebagai suatu tingkat keunggulan yang diinginkan serta pengendalian pada tingkat keunggulan untuk dapat memenuhi apa yang diinginkan konsumen (Tjiptono, Fandy ; Chandra, 2016).

Dimensi ServQual (Service Quality) yang dipakai untuk mengukur kepuasan pelanggan (Tjiptono, 2016), yaitu :

1. Tangibles/nyata adalah kemampuan perusahaan untuk menunjukkan keberadaanya kepada obyek di luar perusahaan, dalam hal ini perusahaan diharapkan mau memberikan pelayanan yang baik.

2. Reliability/kehandalan yaitu kemampuan perusahaan untuk memberikan pelayanan sesuai yang dijanjikan secara akurat.

3. Responsiveness/ kemampuan bereaksi yaitu Kecepatan produsen dalam menanggapi kebutuhan serta keinginan konsumen.

4. Assurance berkaitan dengan kepastian serta jaminan yang diberikan oleh pelaku usaha bagi konsumen seperti pengetahuan yang baik, kesopanan dari staff perusahaan yang dapat meningkatkan kepercayaan konsumen terhadap produk atau jasa yang ditawarkan.

5. Emphaty atau empati adalah perhatian yang diberikan perusahaan bagi konsumennya.

Pelayanan konsumen bukan hanya teerbatas pada transaksi jual beli barang atau jasa, tetapi juga layanan purna jual termasuk didalamnya adalah layanan menerima komplain pembeli. Kualitas pelayanan yang baik akan meningkatkan citra perusahaan di mata konsumen, hal ini secara tidak langsung akan meningkatkan penjualan perusahaan.

\section{Keputusan Pembelian}

Keputusan pembelian merupakan keputusan yang dipilih oleh konsumen untuk menentukan produk serta jasa yang akan mereka konsumsi (Sudaryono, 2016). Sebelum mengambil keputusan ada lima tahapan yang akan dilalui konsumen yaitu mengenali masalah, identifikasi kriteria keputusan, mengevaluasi berbagai alternatif yang ada, keputusan pembelian dan perilaku setelah membeli apakah konsumen puas dan akan melakukan pembelian ulang serta menginformasikan ke orang lain ataukah tidak puas sehingga memtuskan untuk tidak melakukan pembelian ulang bahkan 
meenyampaikan ketidakpuasan ke orang disekitarnya.

Kerangka penelitian dapat digambarkan seperti berikut ini:

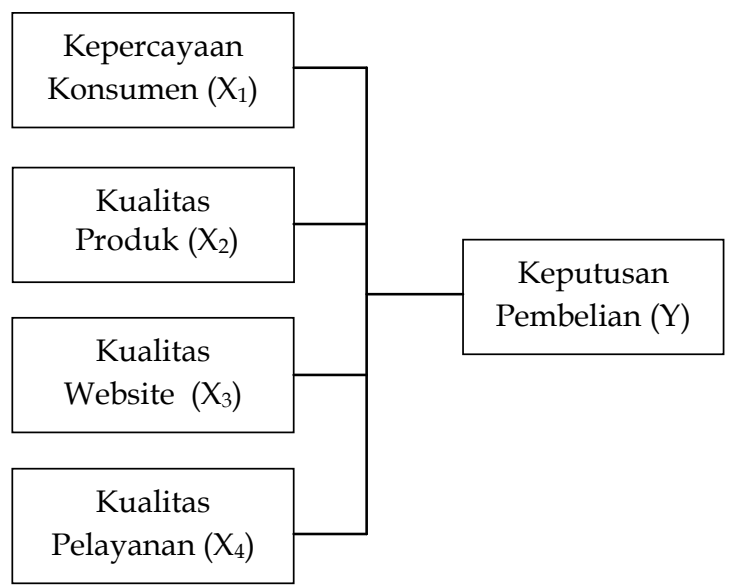

Gambar 1. Kerangka Berpikir

Sumber : Napitupulu (2014) yang dikembangkan untuk penelitian

Berdasarkan kerangka di atas (Napitupulu, Togar Alam; Kartavianus, 2014), maka hipotesis penelitian sebagai beikut:

H1: Kepercayaan Konsumen berpengaruh positif terhadap keputusan pembelian

H2: Kualitas Produk berpengaruh positif terhadap keputusan pembelian

H3: Kualitas Website berpengaruh positif terhadap keputusan pembelian

H4: Kualitas Pelayanan berpengaruh positif terhadap keputusan pembelian

\section{METODE PENELITIAN \\ Pendekatan}

Klasifikasi desain penelitian ini adalah kuantitatif yang menggunakan analisis data berupa angka (Sugiyono, 2008). Penelitian ini dilakukan pada 100 responden yang merupakan konsumen Tokopedia di kota Semarang. Penelitian dilakukan di bulan Januari 2021-Juli 2021.

\section{Populasi Penelitian:}

Populasi penelitian ini adalah konsumen Tokopedia di Semarang. Jumlah populasi berjumlah 100 responden. Jenis populasi penelitian adalah infinite population atau populasi tak terhingga karena konsumen Tokopedia di area Semarang tidak diketahui penulis secara pasti.

\section{Variabel Penelitian, Definisi Operasional}

Variabel independent/ bebas yang digunakan dalam penelitian adalah kepercayaan konsumen $\left(\mathrm{X}_{1}\right)$, kualitas $\operatorname{produk}\left(\mathrm{X}_{2}\right), \quad$ kualitas website $\left(\mathrm{X}_{3}\right)$, kualitas pelayanan $\left(\mathrm{X}_{4}\right)$ dan variabel dependen/terikat adalah keputusan pembelian(Y). Ada lima pilihan jawaban di dalam kuesioner yang dibagikan dari bobot tertinggi sampai bobot terendah yaitu dari Sangat Setuju $=5$, Setuju $=$ 4, Netral $=3$, Tidak Setuju $=2$, Sangat Tidak Setuju $=1$ (menggunakan skala Likert)

Indikator dari variabel penelitian sebagai berikut:

Keputusan Pembelian (Y):

a. Mudah memperoleh barang yang dibutuhkan

b. Dengan belanja online tidak perlu keluar rumah

c. Menghemat waktu dan biaya

Kepercayaan Konsumen $\left(X_{1}\right)$

a. Dapat dipercaya

b. Peduli dengan pelanggan

c. Menepati janji pada pelanggan

Kualitas Produk $\left(\mathrm{X}_{2}\right)$

a. Kualitas produk sesuai dengan yang ditawarkan

b. Produk dapat dievaluasi sebelum dibeli

c. Desain produk menarik

Kualitas Website $\left(\mathrm{X}_{3}\right)$

a. Kemudahan berkomunikasi dengan penjual

b. Situs mudah dipelajari dan dioperasikan

c. Informasi up to date

Kualitas Pelayanan $\left(\mathrm{X}_{4}\right)$

a. Pelayanan yang akurat dan terpercaya

b. Pengiriman barang tepat waktu

c. Adanya jaminan bertransaksi dengan aman

\section{Teknik Analisa Data}

Penelitian ini menggunakan empat variabel bebas, maka analisis yang digunakan adalah regresi linear berganda. Pengujian kualitas data dengan menggunakan uji validitas, uji reliabilitas serta uji asumsi klasik (uji normalitas, multikolonieritas dan heteroskedastisitas).

\section{a. Uji Validitas}

Pertanyaan dalam kuesioner yang sudah diisi akan diuji validitasnya. Hasil pengujian ini akan menunjukkan valid atau tidaknya item-item kuesioner. Kuesioner dibagikan 
kepada 100 konsumen Tokopedia dengan cara memberikan penilaian terhadap atributatribut keputusan pembelian, kepercayaan konsumen, kualitas produk, kualtas website, serta kualitas pelayanan.

\section{b. Uji Reliabilitas}

Uji reliabilitas menunjukkan hasil pengukuran obyek yang sama (Sugiyono, 2017). Kan memberi hasil data sama.

\section{c. Uji Asumsi Klasik}

Uji Normalitas

Uji normalitas menguji apakah variabel bebas/independen serta variabel tergantung/dependen

berdistribusi normal.

\section{Uji Multikolinieritas}

Untuk mengetahui apakah dalam model regresi ditemukan korelasi antar variabel independen digunakan uji multikolinearitas (Ghozali, 2018). Pelaksanaan uji multikolinieritas dengan melihat nilai VIF ke empat variabel bebas. Suatu data dinyatakan bebas dari gejala multikolinieritas, jika nilai VIF di bawah 10.

\section{Uji Heteroskedastisitas}

Ghozali (2018) menyatakan bahwa tujuan uji heteroskedastisitas adalah menguji apakah dalam sebuah model regresi terjadi ketidaksamaan varian dari residual suatu pengamatan ke pengamatan.

\section{d. Analisis Regresi Linear Berganda}

Tujuan dilakukan analisis regresi berganda adalah mengetahui adanya pengaruh dua atau lebih variabel bebas $(X)$ pada variabel terikat $((\mathrm{Y})$.

Uji Statistik $\mathbf{t} /$ Uji Parsial untuk melihat adanya pengaruh secara terpisah (parsia) dari variabel bebas terhadap variabel terikat. Apabila $\mathrm{t}$ hitung $>\mathrm{t}$ tabel atau nilai sig $<0.05$, berarti terdapat pengaruh dari variabel $X$ pada variabel $\mathrm{Y}$ dan sebaliknya.

Uji Statistik F (Uji Simultan) bertujuan untuk mengetahui apakah ada pengaruh simultan dari variabel bebas pada variabel terikat. Apabila nilai F hitung $>\mathrm{F}$ tabel atau sig $<0.05$, maka terdapat pengaruh variabel $X$ secara bersama-sama pada variabel $Y$ dan sebaliknya.
Koefisien Determinasi $\left.\quad \mathbf{R}^{2}\right)$ untuk mengetahui seberapa besar prosentase pengaruh yang diberikan oleh variabel bebas secara bersama-sama pada variabel terikat.

\section{HASIL DAN PEMBAHASAN a. Uji Validitas}

1. Hasil Uji Validitas

\begin{tabular}{|c|c|c|c|}
\hline & $\begin{array}{l}\text { R } \\
\text { hitung }\end{array}$ & R tabel & Keterangan \\
\hline Kepercayaan & & & \\
\hline X11 & .976 & .197 & valid \\
\hline X12 & .844 & .197 & valid \\
\hline X13 & .856 & .197 & valid \\
\hline $\begin{array}{l}\text { Kualitas } \\
\text { Produk }\end{array}$ & & & \\
\hline X21 & .993 & .197 & valid \\
\hline X22 & .908 & .197 & valid \\
\hline X23 & .908 & .197 & valid \\
\hline Kualitas Web & & & \\
\hline X31 & .980 & .197 & valid \\
\hline X32 & .799 & .197 & valid \\
\hline X33 & .802 & .197 & valid \\
\hline Kualitas & & & \\
Pelayanan & & & \\
\hline X41 & .826 & .197 & valid \\
\hline X42 & .785 & .197 & valid \\
\hline X43 & .893 & .197 & valid \\
\hline $\begin{array}{c}\text { Keputusan } \\
\text { Pembelian }\end{array}$ & & & \\
\hline Y1 & .859 & .197 & valid \\
\hline Y2 & .862 & .197 & valid \\
\hline Y3 & .980 & .197 & valid \\
\hline Sumber Data & & & \\
\hline
\end{tabular}

Sumber: Data primer yang diolah (2021)

Nilai $\mathrm{r}$ tabel Product Moment Pearson, taraf signifikan $(\alpha=0.05)$ untuk $N=100$ adalah 0.197 . Validitas menunjukkan kevalidan instrumen dimana nilai $r$ hitung dibandingkan dengan $r$ tabel. Uji terhadap 15 item pertanyaan dari 100 responden Tokopedia memperlihatkan $\mathrm{r}$ hitung mempunyai hasil antara 0.785 - 0.993 dan lebih besar dari $\mathrm{r}_{\text {tabel }}$ yaitu 0.197. Ini memperlihatkan nilai $\mathrm{r}$ hitung $>\mathrm{r}$ tabel, maka seluruh indikator valid.

\section{b. Uji Reliabilitas}

Hasil uji reliabilitas dari variabel bebas dapat dilihat pada Tabel 2. berikut ini :

Tabel 2. Hasil Pengujian Reliabilitas

\begin{tabular}{|l|c|c|}
\hline \multicolumn{1}{|c|}{ Variabel } & $\begin{array}{c}\text { Cronbach's } \\
\text { Alpha }\end{array}$ & Keterangan \\
\hline $\begin{array}{l}\mathrm{X}_{1}=\text { Kepercayaan } \\
\text { Konsumen }\end{array}$ & 0.947 & Reliabel \\
\hline $\mathrm{X}_{2}=$ Kualitas Produk & 0.970 & Reliabel \\
\hline
\end{tabular}


Analisis Kepercayaan Konsumen, Kualitas Produk, Kualitas Website,...

Erlitawati Kaharudin, David Triyono, Alexander Nova Vernando

\begin{tabular}{|l|c|c|}
\hline $\mathrm{X}_{3}=$ Kualitas web & 0.929 & Reliabel \\
\hline $\begin{array}{l}\mathrm{X}_{4}=\text { Kualitas } \\
\text { Pelayanan }\end{array}$ & 0.918 & Reliabel \\
\hline $\begin{array}{l}\mathrm{Y}=\text { Keputusan } \\
\text { Pembelian }\end{array}$ & 0.952 & Reliabel \\
\hline
\end{tabular}

Sumber: Data primer yang diolah (2021)

Tabel 2. menunjukkan vahwa hasil uji reliabilitas variabel $\mathrm{X}_{1}, \mathrm{X}_{2}, \mathrm{X}_{3}, \mathrm{X}_{4}, \mathrm{Y}$ menunjukkan nilai Cronbach's Alpha lebih besar dari 0.6, maka variabel kepercayaan konsumen, kualitas produk, kualitas website, kualitas pelayanan dan keputusan pembelian adalah reliabel sehingga layak digunakan sebagai alat ukur kuesioner dalam penelitian.

\subsection{Uji Asumsi Klasik}

\section{a. Uji Normalitas}

Uji Kolmogorov Smirnov terhadap nilai residual model regresi digunakan untuk pengujian asumsi normalitas, hasilnya seperti terdapat pada Tabel3.

Tabel 3. Uji Kolmogorov Smirnov

\begin{tabular}{|l|l|l|}
\hline $\begin{array}{l}\text { One-Sample } \\
\text { Test }\end{array}$ & $\begin{array}{l}\text { Unstandar } \\
\text { dized } \\
\text { Residual }\end{array}$ \\
\hline \multirow{2}{*}{} & & 100 \\
\hline $\mathrm{N}$ & Mean & .0000000 \\
\cline { 2 - 3 } $\begin{array}{l}\text { Normal } \\
\text { Parameters }\end{array}$ & $\begin{array}{l}\text { Std. } \\
\text { Deviation }\end{array}$ & 2.01303500 \\
\hline $\begin{array}{l}\text { Most } \\
\text { Extreme } \\
\text { Differences }\end{array}$ & Absolute & .069 \\
\cline { 2 - 3 } & Positive & .044 \\
\cline { 2 - 3 } Negative & -.069 \\
\hline Kolmogorov-Smirnov Z & .689 \\
\hline Asymp. Sig. (2-tailed) & .200 \\
\hline \multicolumn{2}{|l|}{ Sumber: Data primer yang diolah (2021) } \\
\hline
\end{tabular}

Berdasarkan hasil uji normalitas diketahui nilai signifikansi 0,200. Karena nilai signifikansi > 0,05 maka dapat disimpulkan bahwa nilai residual berdistribusi normal.

\section{b. Uji Multikolinearitas}

Pengujian multikolinearitas menggunakan nilai VIF dan toleran, seperti ditunjukkan pada Tabel 4. di bawah ini:

Tabel 4. Uji Multikolinearitas

\begin{tabular}{|l|c|c|}
\hline \multicolumn{1}{|c|}{ Variabel } & \multicolumn{2}{c|}{ Collinearity Statistics } \\
\cline { 2 - 3 } & Tolerance & VIF \\
\hline $\begin{array}{l}\mathrm{X}_{1}=\text { Kepercayaan } \\
\text { Konsumen }\end{array}$ & .729 & 1.372 \\
\hline
\end{tabular}

\begin{tabular}{|l|c|c|}
\hline $\mathrm{X}_{2}=$ Kualitas Produk & .721 & 1.387 \\
\hline $\mathrm{X}_{3}=$ Kualitas web & .944 & 1.060 \\
\hline $\mathrm{X}_{4}=$ Kualitas Pelayanan & .914 & 1.094 \\
\hline \multicolumn{2}{|c|}{ Sumber : Data primer yang diolah (2021) }
\end{tabular}

Pada penelitian ini diperoleh nilai VIF 1.372, 1.387, 1.060, 1.094 sedangkan nilai toleran 0.729, $0.721,0.944,0.914$. Karena nilai VIF di bawah 10 dan toleran di atas 0.1, maka dapat disimpulkan model regresi pengaruh kepercayaan konsumen, kualitas produk, kualitas web dan kualitas pelayanan terhadap keputusan pembelian tidak terdapat gejala multikolinearitas.

\section{c. Uji Heteroskedastisitas}

Tabel 5. menunjukkan hasil pengujian Heteroskedastisitas, sebagai berikut :

\section{Tabel 5. Uji Heteroskedastisitas}

\begin{tabular}{|l|c|}
\hline \multicolumn{1}{|c|}{ Variabel } & Sig \\
\hline$X_{1}=$ Kepercayaan Konsumen & 0.444 \\
\hline$X_{2}=$ Kualitas Produk & 0.172 \\
\hline$X_{3}=$ Kualitas web & 0.623 \\
\hline$X_{4}=$ Kualitas Pelayanan & 0.087 \\
\hline \multicolumn{2}{|c|}{ Sumber : Data primer yang diolah (2021) }
\end{tabular}

Dari tabel di atas nilai signifikansi $>0.05$, maka hal ini mengindikasikan tidak terjadi heteroskedastisitas.

\subsection{Uji t}

Tabel 6. menunjukkan hasil pengujian variabel bebas secara parsial, sebagai berikut:

Tabel 6. Hasil Uji Parsial

\begin{tabular}{|c|c|c|c|c|c|}
\hline & \multicolumn{2}{|c|}{$\begin{array}{c}\text { Unstandardiz } \\
\text { ed } \\
\text { Coefficients }\end{array}$} & \multirow[t]{2}{*}{$\begin{array}{l}\text { Stand } \\
\text { Coef }\end{array}$} & \multirow[t]{2}{*}{$t$} & \multirow[t]{2}{*}{ Sig. } \\
\hline & B & $\begin{array}{l}\text { Std. } \\
\text { Error }\end{array}$ & & & \\
\hline (Constant) & -1.044 & 2.118 & & -.493 & .623 \\
\hline $\begin{array}{c}\mathrm{X}_{1}=\text { Kepercaya- } \\
\text { an }\end{array}$ & .328 & .088 & .344 & 3.735 & .000 \\
\hline $\begin{array}{c}\mathrm{X}_{2}=\text { Kualitas } \\
\text { Produk }\end{array}$ & .330 & .085 & .361 & 3.893 & .000 \\
\hline $\begin{array}{c}\mathrm{X}_{3}=\begin{array}{c}\text { Kualitas } \\
\text { web }\end{array} \\
\text {. }\end{array}$ & .285 & .115 & .201 & 2.480 & .015 \\
\hline $\begin{array}{l}\mathrm{X}_{4}=\text { Kualitas } \\
\text { Pelayanan }\end{array}$ & .162 & .080 & .166 & 2.018 & .046 \\
\hline
\end{tabular}

Sumber : Data primer yang diolah (2021)

$\mathrm{t}$ tabel $=\mathrm{t}(\dot{\alpha} / 2 ; \mathrm{n}-\mathrm{k}-1)=\mathrm{t}(0,025 ; 100-4-1)=1.985$

Dari tabel di atas terdapat pengaruh variabel $X$ pada variabel $Y$ karena nilai sig < 0.05 atau $t$ hitung $>t$ tabel, maka disimpulkan secara parsial variabel kepercayaan 
konsumen, kualitas produk, kualitas website serta kualitas pelayanan berpengaruh signifikan terhadap keputusan pembelian/decision making.

\subsection{Uji F}

Tabel 7. menunjukkanhasil pengujian keempat variabel bebas secara bersama-sama atau simultan, yaitu:

Tabel 7. Hasil Uji Simultan

\begin{tabular}{|c|c|c|}
\hline Model & \multicolumn{1}{|c|}{ F } & Sig. \\
\hline Regression & 16.636 & $.000^{\mathrm{a}}$ \\
\hline \multicolumn{2}{|c|}{} \\
\multicolumn{2}{|c|}{ Sumber : Data primer yang diolah (2021) }
\end{tabular}

F tabel $=\mathrm{f}(\mathrm{k} ; \mathrm{n}-\mathrm{k})=\mathrm{F}(2: 10)=2.466$

Dari tabel di atas nilai sig $<0.05, \mathrm{~F}$ hitung $>\mathrm{F}$ tabel. Nilai F hitung sebesar $16.636>2.466$, dengan nilai signifikansi $0.000<0.05$, jadi secara simultan variabel kepercayaan konsumen, kualitas produk, kualitas website dan kualitas pelayanan berpengaruh signifikan terhadap keputusan pembelian.

\subsection{Koefisien Determinasi $\left(\mathbf{R}^{2}\right)$}

Tabel 8. Di bawah ini menunjukkan nilai koefisien determinasi.

Tabel 8. Nilai Koefisien Determinasi

\begin{tabular}{|l|c|c|c|c|}
\hline Model & $\mathbf{R}$ & $\begin{array}{c}\mathbf{R} \\
\text { Square }\end{array}$ & $\begin{array}{c}\text { Adjusted } \\
\text { R Square }\end{array}$ & $\begin{array}{c}\text { Std. } \\
\text { Error of } \\
\text { the } \\
\text { Estimate }\end{array}$ \\
\hline 1 & $.842^{\mathrm{a}}$ & .712 & .727 & 1.365 \\
\hline
\end{tabular}

Sumber : Data primer yang diolah (2021)

Tabel di atas menunjukkan koefisien determinasi/ Adjusted $\mathrm{R}^{2}=0.727=72.7 \%$. Dapat diartikan bahwa $72.7 \%$ variabel keputusan pembelian bisa dijelaskan oleh variabel kepercayaan konsumen, kualitas produk, kualitas web dan kualitas pelayanan, sisanya sebesar $27.3 \%$ dipengaruhi oleh variabel lain di luar model.

\subsection{Hasil Uji Hipotesis}

Dari Tabel 7. hasil pengolahan data dengan bantuan program SPSS, maka didapatkan model persamaan regresi sebagai berikut :

$\mathrm{Y}=-1.044+0.328 \mathrm{X} 1+0.330 \mathrm{X} 2+0.285 \mathrm{X} 3+$ $0.162 X 4$

Jika nilai signifikansi < dari nilai $\mathrm{a}=0,05$, maka hipotesis terdukung.

\section{Pengujian hipotesis dengan uji $t$}

Hipotesis Pertama (H1)

Nilai sig untuk $\mathrm{X}_{1}$ terhadap $\mathrm{Y}$ adalah $0.00<$ 0.05 , sehingga $\mathrm{H} 1$ diterima. Nilai thitung 3.735 $>$ dari $t$ tabel 1.985, berarti ada pengaruh positif kepercayaan konsumen $\left(X_{1}\right)$ terhadap keputusan pembelian $(\mathrm{Y})$.

Hipotesis Kedua (H2)

Nilai sig untuk $\mathrm{X}_{2}$ terhadap $\mathrm{Y}$ adalah $0.00<$ 0.05 , sehingga $\mathrm{H} 2$ diterima. Nilai t hitung 3.893 $>$ dari $t$ tabel 1.985, ada pengaruh positif kualitas produk $\left(\mathrm{X}_{2}\right)$ pada keputusan pembelian (Y).

\section{Hipotesis Ketiga (H3)}

Diketahui nilai sig untuk $\mathrm{X}_{3}$ terhadap $\mathrm{Y}$ adalah $0.00<0.05$, sehingga H3 diterima. Nilai $t$ hitung $2.480>$ dari $\mathrm{t}$ tabel 1.985 , berarti ada pengaruh positif kualitas web $\left(X_{3}\right)$ terhadap keputusan pembelian $(\mathrm{Y})$.

\section{Hipotesis Keempat (H4)}

Nilai sig untuk $\mathrm{X}_{4}$ terhadap $\mathrm{Y}$ adalah $0.00<$ 0.05, sehingga H4 diterima. Nilai t hitung 2018 $>$ dari $\mathrm{t}$ tabel 1.985, berarti ada pengaruh positif kualitas pelayanan $\left(X_{4}\right)$ terhadap keputusan pembelian (Y).

\section{PEMBAHASAN}

Penelitian ini menunjukkan bahwa kepercayaan konsumen, kualitas produk, kualitas web dan kualitas pelayanan memiliki pengaruh positif terhadap keputusan pembelian konsumen. Secara empiris hasil penelitian membuktikan bahwa kepercayaan konsumen, kualitas produk, kualitas web dan kualitas pelayanan secara bersama-sama atau simultan berpengaruh signifikan terhadap keputusan pembelian.

\section{KESIMPULAN}

Kesimpulan dari hasil analisis adalah sebagai berikut :

1. Dari pengujian regresi linear berganda maka dapat disimpulkan bahwa variabel kepercayaan konsumen $\left(X_{1}\right)$, kualitas produk $\left(X_{2}\right)$, kualitas website $\left(X_{3}\right)$ dan kualitas pelayanan $\left(\mathrm{X}_{4}\right)$ memiliki pengaruh positif serta signifikan pada keputusan pembelian di Tokopedia. Hal ini mendukung hipotesis bahwa kepercayaan konsumen, kualitas produk, kualitas website serta kualitas pelayanan memiliki pengaruh positif pada keputusan pembelian di Tokopedia. 
2. Dari Uji $\mathrm{T} /$ pengujian parsial menunjukkan variabel kepercayaan konsumen $\left(\mathrm{X}_{1}\right)$, kualitas $\operatorname{produk}\left(\mathrm{X}_{2}\right)$, kualitas website $\left(\mathrm{X}_{3}\right)$ serta kualitas pelayanan $\left(\mathrm{X}_{4}\right)$ berpengaruh positif dan signifikan pada variabel keputusan pembelian di Tokopedia.

3. Dari Uji F/pengujian secara simultan/serempak menunjukkan masingmasing variabel mempunyai pengaruh yang signifikan secara simultan.

\section{DAFTAR PUSTAKA}

Annur, C. M. (n.d.). Tingkat Penetrasi Internet Indonesia Urutan Ketujuh se-Asia Tenggara. https://databoks.katadata.co.id/datapub lish/2020/09/28/tingkat-penetrasiinternet-indonesia-urutan-ketujuh-seasia-tenggara

Ghozali, I. (2018). Aplikasi Analisis Multivariate dengan Program IBM SPSS 25. Badan Penerbit Universitas Diponegoro.

Kotler, Philip; Keller, K. L. (2016). Marketing Management (16th ed.). Pearson Education, Inc.

Napitupulu, Togar Alam; Kartavianus, O. (2014). A Strucural Equations Modeling of Purchasing Decision Through ECommerce. Journal of Theoritical and Applied Information Technology, 60(2), 358364.

Sudaryono. (2016). Manajemen Pemasaran Teori dan Implementasi. CV Andi Offset.

Sugiyono. (2008). Metode Penelitian Kuantitatif Kualitatif dan RED,. Alfabeta.

Tjiptono, Fandy; Chandra, G. (2016). Service Quality \& Satisfaction (4th ed.). CV Andi Offset.

Tjiptono, F. (2016). Service, Quality $\mathcal{E}$ satisfaction. CV Andi Offset. 